Sādhanā Vol. 39, Part 4, August 2014, pp. 989-997. (C) Indian Academy of Sciences

\title{
Applicability of Doppler weather radar based rainfall data for runoff estimation in Indian watersheds - A case study of Chennai basin
}

\author{
V S JOSEPHINE ${ }^{1, *}$, B V MUDGAL ${ }^{1}$ and S B THAMPI ${ }^{2}$ \\ ${ }^{1}$ Centre for Water Resources, Anna University, Chennai 600 025, India \\ ${ }^{2}$ Cyclone Detection Radar, India Meteorological Department, Chennai 600 001, India \\ e-mail: josephine.vanaja@yahoo.com
}

MS received 19 June 2013; revised 18 March 2014; accepted 27 March 2014

\begin{abstract}
Traditionally, India has been vulnerable to various hazards such as floods, droughts and cyclones. About $8 \%$ of the total Indian landmass is prone to cyclones. A number of Doppler weather radars are installed in India and their products are utilized for weather predictions and detection of cyclones approaching the Indian coast. Radar-based hydrological studies in various countries have proven that computation of runoff using radar rainfall data could outperform rain gauge network measurements. There are no reported studies on their utilization for hydrological modelling and/or flood-related studies in Indian river basins. A comparison study between Doppler weather radar (DWR) derived rainfall data and the conventional rain gauge data was carried out with hourly inputs at one of the watersheds of Chennai basin, Tamil Nadu, India using HEC-HMS model. The model calibration and validation were performed by comparing the simulated outflow with the observed daily outflow data. The calibrated model was used to predict runoff from two post-monsoon cyclonic storm events with hourly inputs. It was noticed that the discrepancy in the runoff volume was small, but the difference in the peak flow was substantial. Additionally, there was a variation at the time to peak flow using daily and hourly inputs. The results show that the use of radar data may be optional for runoff volume estimation for the watersheds with sufficient rain gauge density, but highly desirable for peak flow and time to peak estimation. Therefore, the DWR derived rainfall data is a promising input for runoff estimation, especially in urban flood modelling.
\end{abstract}

Keywords. Radar rainfall; calibration factor; runoff estimation; HEC-HMS model.

\section{Introduction}

Precipitation is the primary input to a watershed system. Hydrological analysis can be performed with confidence only if the precipitation input is adequately measured in spatial and temporal

*For correspondence 
extents. An extremely dense rain gauge network is needed for efficient rainfall-runoff estimation of a watershed. Suresh (2010) stated that a dense network of $2 \times 2 \mathrm{~km}$ might be required for planning purposes in India. However, owing to the practical difficulties, an acceptable density of the rain gauge network was proposed as $4 \times 4 \mathrm{~km}$ but this network density is also functionally impractical in view of topographical and terrain constraints, cost restrictions and maintenancerelated problems. At present, India has one rain gauge for every $3402 \mathrm{sq} \mathrm{km}$ on an average (Guhathakurta \& Rajeevan 2008).

Alternatively, the radar's ability to provide detailed information, in both space and time with precipitation patterns is unsurpassed by rain gauges. Radar is an active remote-sensing system operating at microwave wavelengths. It works under the principle of Rayleigh scattering. The sensor transmits a microwave signals towards a target and detects the backscattered radiation. The target scatters some pulses back to the receiver by the process of reflection, refraction and scattering. The intensity of the returned pulse and the return time is recorded. The strength of the backscattered signal is measured to discriminate between different targets; and the time delay between the transmitted and reflected signals determines the distance to the target. The reflectivity $(\mathrm{Z})$ is then converted to rainfall intensity $(\mathrm{R})$ using Z-R relationship.

In 2002, India Meteorological Department (IMD) has installed one S-band Doppler Weather Radar (DWR) at Cyclone Detection Radar centre (CDR), Chennai. Suresh et al (2005) proposed the present Z-R Relationship $\left(Z=267 \mathrm{R}^{1.345}\right)$ for the S-band DWR operating in CDR, Chennai for the Surface Rainfall Intensity (SRI) computation for all the seasons and types of rainfall. DWR provides good information on rainfall data, wind speed and direction, temperature, humidity, air pressure and visibility at $500 \times 500 \mathrm{~m}$ spatial and $15 \mathrm{~min}$ temporal resolution. Bhatnagar et al (2003) provided an overview of radar principles, digital signal processors, Doppler principle and special features and products available from the S-band DWR, Chennai (Tamil Nadu, India). Several studies in India have highlighted the expedience of the use of radar data for weather forecasting (Sarkar \& Kumar 2007; Mazumdar et al 2009; Roy et al 2010; Bhowmik et al 2011). Presently, there seems to be a lack of utilization of the DWR rainfall data for hydrological modelling and flood-related studies in India.

Many researchers have simulated rainfall-runoff processes for various watersheds in different countries using data from weather radars and rain gauges. Mapiam et al (2009) estimated runoff at four stations in the upper Ping river basin, Northern Thailand using 35 rain gauges and one Sband Doppler radar rainfall data. The results illustrate that the radar rainfall data produced more accurate runoff hydrographs than the daily rain gauge rainfall data in terms of the overall hydrograph and peak flow estimations. Jeremy (2011) estimated peak flow rates and runoff volumes due to a heavy rainfall event at Kenora, Ontario. The study inferred that radar could supply additional rainfall amount and durations for an area that did not have a meteorological gauge station within the watershed. Ruiz-Villanueva et al (2012) examined the flash flood peaks on the Starzel river basin in Southwest Germany. They concluded that the availability of high-resolution radar rainfall data in conjunction with a rain gauge network provided the opportunity to study in detail the hydro meteorological and hydrological mechanisms associated with the extreme storm and the ensuing flood.

A special issue on 'radar rainfall data analyses and applications' edited by Pathak (2013) contains 17 papers. Some of the relevant literature is discussed here. Habib et al (2013) compared the different radar-based precipitation products of the National Weather Service (NWS) Multisensor Precipitation Estimator (MPE) algorithm with WSR-88 Doppler products and rain gauge data from dense, carefully maintained experimental rain gauges. They identified that the most efficient rainfall products could be obtained from assigning the mean-field bias adjustment to the radar product. Kitzmiller et al (2013) described various techniques utilized by the NWS to 
prepare gridded rainfall data for input into hydrologic forecasting models and decision-making systems for river forecasting, flood and flash flood warning and other hydrologic monitoring purposes. Mazari et al (2013) compared the NEXRAD Digital Storm-total Precipitation (DSP) products from two radar stations with an observation from a network of 50 rain gauges in the Upper Guadalupe River Basin located in Texas. The rainfall data comparisons were conducted at six minutes, one hour and storm-total accumulation temporal scales. They noticed strong range dependence from radar estimates for one of the radar stations. Teague et al (2013) conducted rainfall-runoff study at a watershed near Houston, Texas with a fully distributed Vflo rainfallrunoff model. The hydrograph comparisons exhibited that the outflow using radar data input matched the observed streamflow in terms of volume and peak flow.

The objective of this study is to simulate the rainfall-runoff processes at one of the watersheds of Chennai basin to confirm the applicability of weather radar-based runoff estimation for Indian watersheds. Rain gauge rainfall data and S-band DWR derived rainfall data at hourly intervals were utilized for two cyclonic storm events.

\section{Study area}

Chennai basin is located between latitudes of $12^{\circ} 40^{\prime} \mathrm{N}$ and $13^{\circ} 40^{\prime} \mathrm{N}$ and longitudes of $79^{\circ} 10^{\prime} \mathrm{E}$ and $80^{\circ} 25^{\prime} \mathrm{E}$ in Tamil Nadu, India. It is trisected by two rivers namely the Adyar and the Cooum. These rivers have their own catchment area to drain the surface runoff. The Adyar watershed is one of the gauged watersheds in the Chennai basin. It is a combination of both rural and urban areas with $39 \%$ under metropolitan area and the remaining $61 \%$ under rural area. The Chennai basin has a tropical climate with a maximum temperature of around $35-42^{\circ} \mathrm{C}$ and a minimum temperature of around $19-28^{\circ} \mathrm{C}$.

The DWR derived rainfall data is available at a reliable precision for a $100 \mathrm{~km}$ radius from the DWR station, Chennai (Suresh 2012). Adyar watershed is within a $100 \mathrm{~km}$ radius from DWR station and hence it was chosen as the study area. The watershed was delineated using the Indian Remote Sensing (IRS) satellite Cartosat-1 30 m Digital Elevation Model (DEM). Figure 1 shows the study area DEM with Doppler weather radar location and the influencing rain gauge stations. The areal extent of the watershed is $631.79 \mathrm{sq} \mathrm{km}$. The DEM was utilized to define the stream network and disaggregate the watershed into a series of interconnected subbasins in HEC-GeoHMS software.

\section{Rainfall inputs}

There are nine influencing rain gauges at the watershed, of which only two are recording type rain gauges. The rainfall data is available on a daily basis for non-recording rain gauges and hourly basis for automatic rain gauges. The rain gauge rainfall data was collected from the State Ground and Surface Water Resources Data Centre, Tharamani, Chennai. The daily rainfall data was converted into an hourly rainfall data for the non-recording rain gauges using IMD empirical reduction formula (Rashid et al 2012). The daily and hourly radar rainfall data with $500 \mathrm{~m}$ spatial resolution was collected from CDR, Chennai. Software tools were developed for reformatting the radar data into the Hydrologic Engineering Center-Data Storage System (HEC-DSS) format required by the Hydrological Modeling System (HEC-HMS) event model. HEC-DSS is a database file and is intended to store and retrieve spatial-oriented gridded data (USACE 2009). 


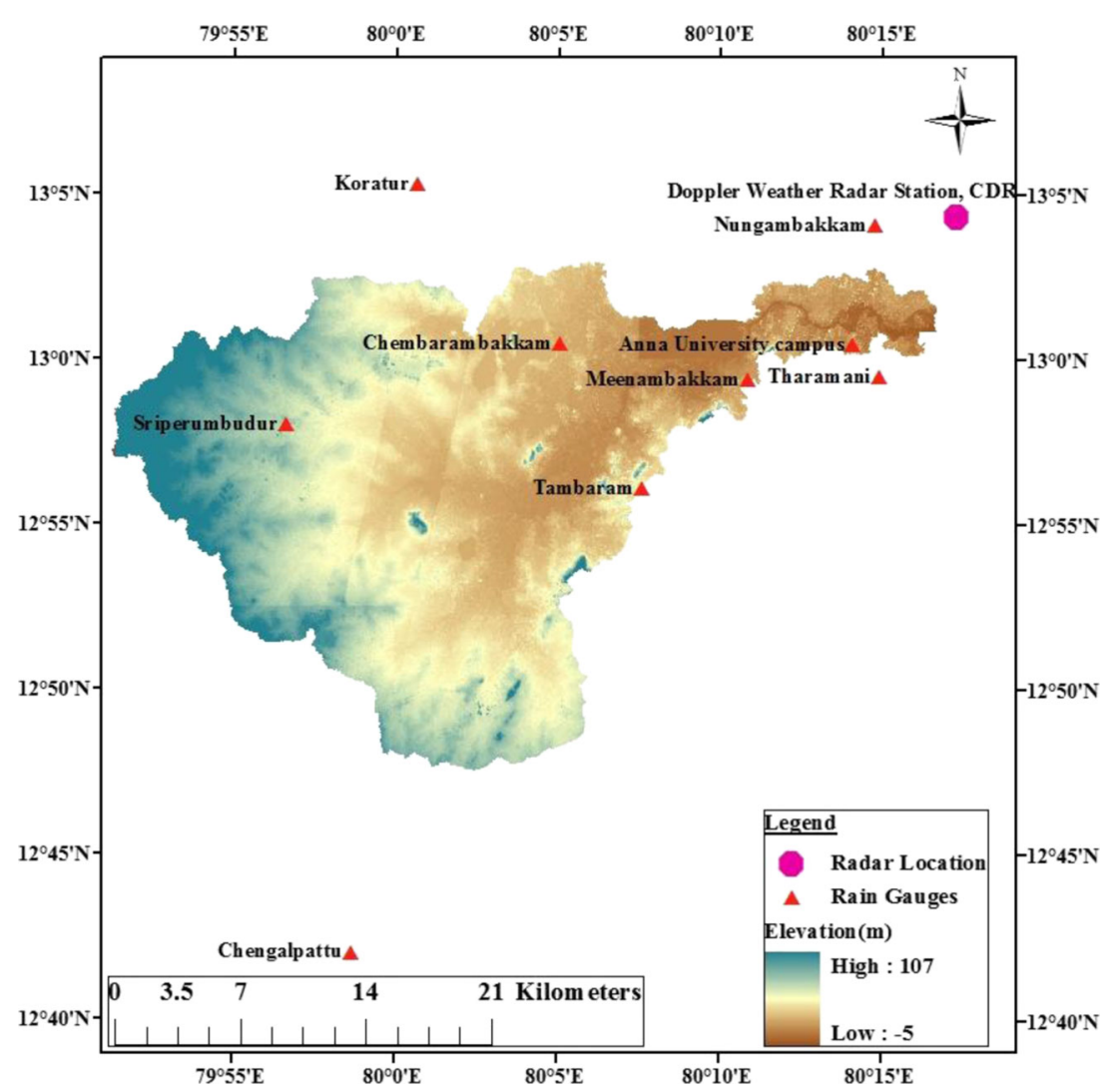

Figure 1. Cartosat DEM of the watershed with DWR station and rain gauges locations.

The comparison of DWR rainfall data with the rain gauge values indicated that the Z-R relationship developed by IMD was underestimating the rainfall for the entire study period. Subsequently, the radar rainfall data required adjustment prior to its utilization as the input to the hydrological model. As a general rule, the automatic rain gauges must be used for precise radar rainfall calibration. Since the study area has inadequate automatic rain gauges, both recording as well as non-recording rain gauges were considered for the radar data calibration. For this research, the calibration factor was worked out in two ways.

In the first method, radar rainfall values were accumulated at the watershed for each event and were compared with the rain gauge rainfall accumulation. The calibration factor was estimated using the equation $\sum \mathrm{G}_{\mathrm{i}} / \mathrm{R}_{\mathrm{i}}$. In the second method, a scatter plot was drawn between the accumulated values of radar rainfall data and rain gauge data for each event. A trend line was drawn by setting the intercept to zero, to study the correlation between two different inputs and the calibration factor was identified from the linear regression equation. It was noted that the calibration factors were nearly identical by both the methods for all scenarios. However, for this study, the second method was used to work out the calibration factor. Figure 2 shows the methods used for finding the calibration factor for the Nisha storm event. The calibration factor of 1.342 was obtained by the first method and 1.344 was attained by the second method. Because of the inadequacy of the automatic rain gauges at the watershed, the calibration factor of 1.344 was applied 


\begin{tabular}{|l|r|r|r||}
\hline Station name & $\begin{array}{c}\text { Rain gauge } \\
\text { data (mm) }\end{array}$ & $\begin{array}{r}\text { Radar data } \\
\text { (mm) }\end{array}$ & $\begin{array}{c}\text { Calibration } \\
\text { factor for } \\
\text { each station }\end{array}$ \\
\hline Aungambakkam & 526.8 & 426.49 & 1.235 \\
\hline Tharamani & 433 & 338.39 & 1.280 \\
\hline Meenambakkam & 723.3 & 380.5 & 1.901 \\
\hline Tambaram & 513 & 393.4 & 1.304 \\
\hline Chembarambakka & 616 & 427.7 & 1.440 \\
\hline Koratur & 462 & 400.48 & 1.154 \\
\hline Sriperumpudur & 490.5 & 378.3 & 1.297 \\
\hline Anna University & 433 & 363.69 & 1.191 \\
\hline Chengalpattu & 456.5 & 356.7 & 1.280 \\
\hline
\end{tabular}

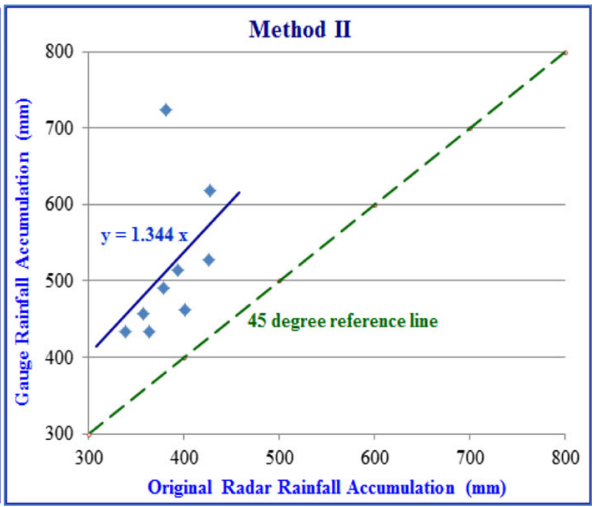

Figure 2. Radar rainfall calibration methods for Nisha storm event.

to the radar rainfall values. Similarly, the calibration factor was worked out as 1.407 and 1.786 for Phyan and Jal storm events, respectively and shown in table 1. The radar derived rainfall data was adjusted by multiplying the original rainfall values by the respective calibration factor.

After the calibration, there was an agreement between the accumulated radar and rain gauge values with minimum Mean Absolute Percentage Error (MAPE). The MAPE was reduced from 26 to $1 \%$ for Nisha storm event, from 29 to $1 \%$ for Phyan storm event and from 46 to 3\% for Jal storm event.

\section{Hydrological model}

HEC-HMS hydrological model, based on the Geographical Information Systems (GIS) and the Remote-Sensing (RS) technique, was chosen for simulating the rainfall-runoff response. Basin model, meteorological model and control specification are the main components for this runoff simulation. Using HEC-GeoHMS inputs, a basin model was created in the HEC-HMS. The excess rainfall was estimated using the Soil Conservation Service-Curve Number (SCS-CN) method. SCS Unit Hydrograph (SCS UH) method converts surplus rainfall into runoff at the subbasin outlet. The Muskingum routing method was used for streamflow routing.

The meteorological model of the HEC-HMS handles the atmospheric conditions over the watershed. In this study, the gauge weight method was selected for the rain gauge rainfall in the meteorological model analysis. The rainfall at each of the rain gauge stations was distributed over the watershed and the weight of each gauge was calculated using the Thiessen polygon technique

Table 1. Calibration factors for the study period.

\begin{tabular}{llll}
\hline Name of the cyclonic storm event & Nisha (2008) & Phyan (2009) & Jal (2010) \\
\hline Rainfall intensity (mm/h) & 16.17 & 15.02 & 5.49 \\
Rainfall under estimation $(\%)$ & 26 & 29 & 46 \\
Calibration factor & 1.344 & 1.407 & 1.786 \\
\hline
\end{tabular}


in HEC-GeoHMS software. Gridded precipitation method was applied for radar rainfall inputs. The HEC-HMS control specifications define the simulation start and stop time; it should match with the time windows of the gridded precipitation data.

Coastal region of Eastern part India receives a significant amount of rainfall from cyclonic storms. Cyclonic storm Nisha developed in the Indian Ocean during the 2008 and headed northwest towards South Karnataka after making landfall in Tamil Nadu. In the year 2009, Phyan cyclone gave intense rainfall to Tamil Nadu. During 2010, cyclone Jal brought heavy rainfall to Chennai. Cyclones Nisha, Phyan and Jal were considered for the analysis.

The observed flow data was available at daily intervals for Nisha and Jal storm events and hence the simulation was executed at a daily time step for model calibration and validation. HEC-HMS has two search methods and seven objective functions to find out the optimal parameter value for model calibration. The univariate gradient search method evaluates and adjusts one parameter at a time, whereas Nelder and Mead search method adjusts all the parameters simultaneously (USACE 2010). For Nisha storm event, the percent error in peak object function with univariate gradient search method was used to adjust the input Curve Number (CN) parameter value using rain gauge input. The optimal parameter value was reached after 45 iterations. This was attained by reducing the difference between the computed flow and observed flow by adjusting the $\mathrm{CN}$ parameter value. The resultant computed flow is called optimized flow and shown in figure 3 . As a result of optimization, the curve number value was increased by $22.38 \%$ for all the sub-basins.

HEC-HMS model was validated by simulating the rainfall-runoff processes using rain gauge and radar rainfall inputs for the Jal storm event. A graphical comparison of a scatter plot between the simulated and measured flow is widely used for examining the model performance (Kathol et al 2003; Hammouri \& El-Naqa 2007; Knapp et al 2007). Hence, scatter plots were drawn between the observed flow and simulated outflows using two types of rainfall inputs as shown in figure 4, to assess the HEC-HMS model. The correlation coefficient $\left(\mathrm{R}^{2}\right)$ of 0.946 was attained for rain gauge inputs and 0.975 was achieved for the calibrated radar inputs. The results indicate that the computed runoff using HEC-HMS model and observed runoff are in agreement. The rainfall-runoff simulations were then executed for two cyclonic storm events with hourly rainfall inputs.

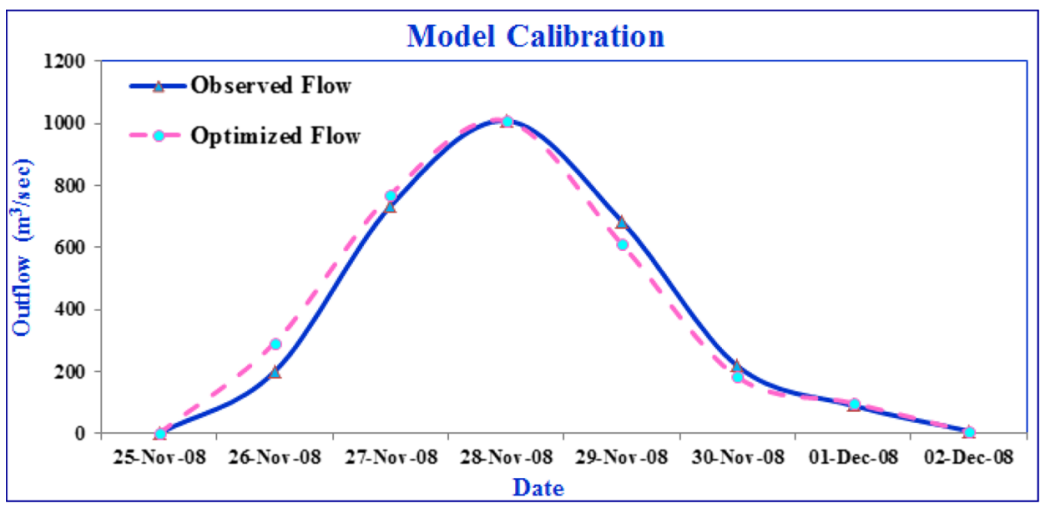

Figure 3. HEC-HMS model calibration for Nisha storm event. 


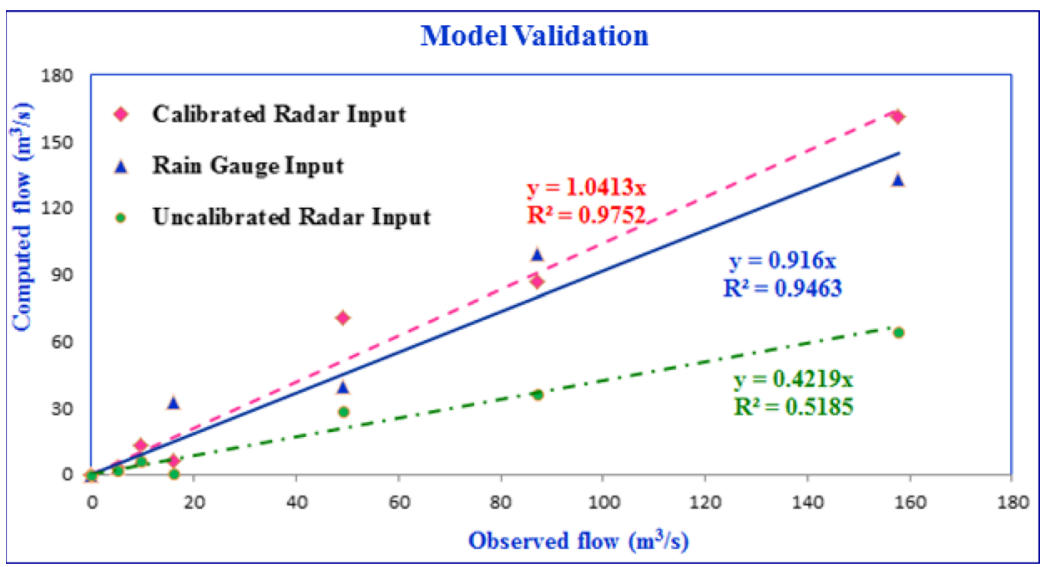

Figure 4. Observed flow comparison with simulated outflows.

\section{Results and discussion}

The CDR's Doppler weather radar underestimates the rainfall for the three cyclonic storm events. Therefore, the systematic bias was removed by applying the calibration factor. The rainfallrunoff process was simulated using rain gauge data and calibrated radar hourly data as inputs for Jal and Phyan cyclonic storm events and the results are shown in figures 5 and 6 . The comparison reveals that the variation in the total volumes and peak discharges are about 25 and $22 \%$ for Phyan; 12 and $37 \%$ for Jal events. The study area has sufficient rain gauges density and it may capture the spatial variability of rainfall on the watershed correctly. Hence the differences in the runoff volumes are small. Therefore, the use of radar rainfall data may be optional for runoff volume estimation. There appears to be considerable difference in the peak flow of about $22 \%$ for the Phyan storm and $37 \%$ for the Jal storm. The daily rainfall data are converted into hourly rainfall data using the empirical formula; the resultant reduced rainfall data might perhaps be at variance from the actual temporal distribution of rainfall and leads to discrepancy in the peak flow. Furthermore, the time to peak flow is at variance using daily and hourly inputs.

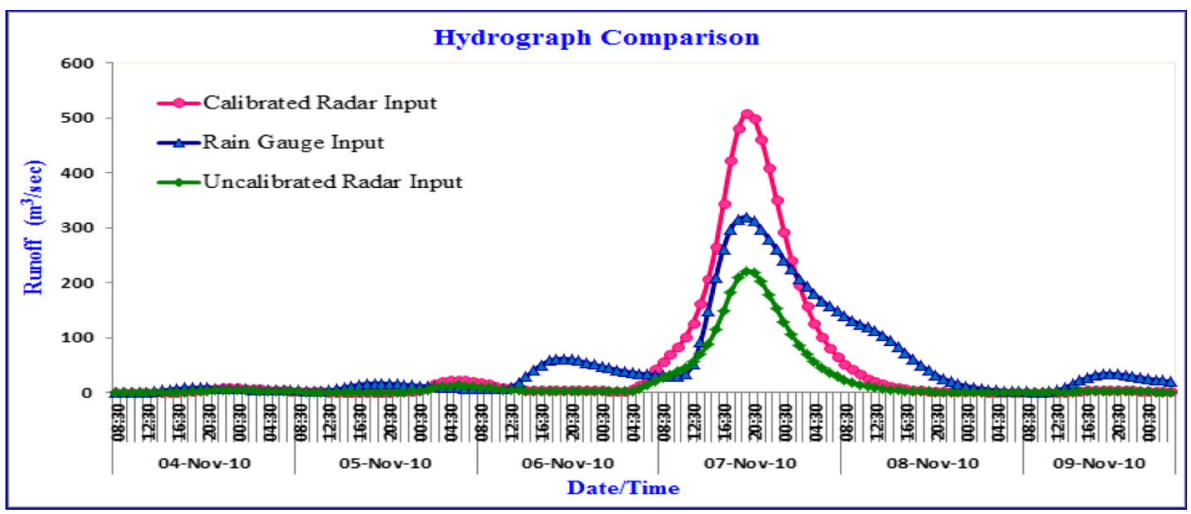

Figure 5. Hydrograph comparisons with hourly inputs for Jal. 


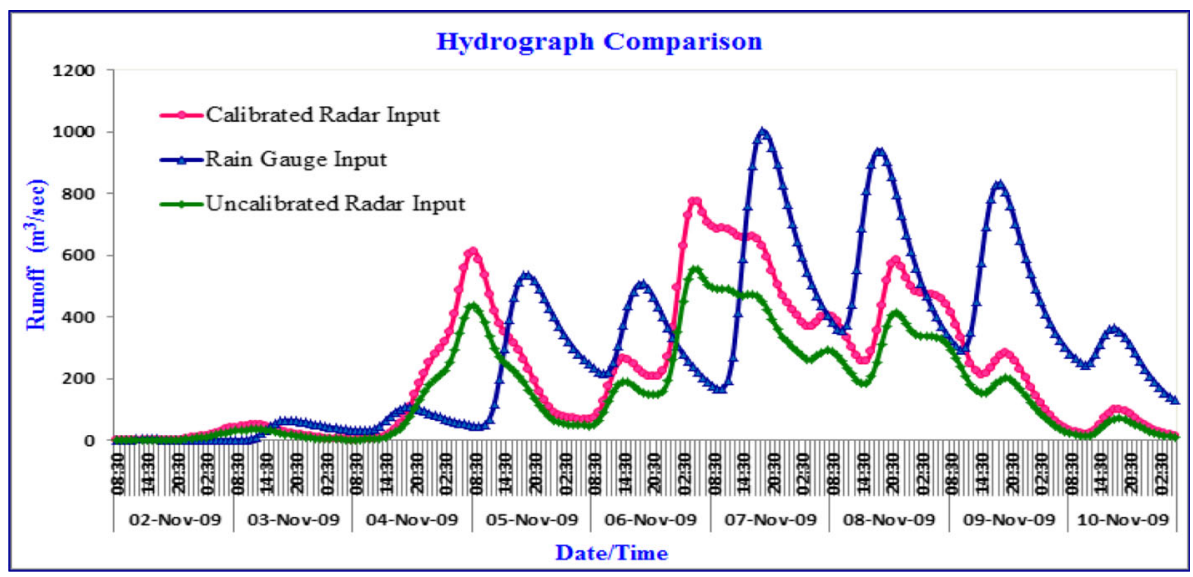

Figure 6. Hydrograph comparisons with hourly inputs for Phyan.

In the Chennai basin, the Adyar River inundated its banks and caused extensive flood damages to Chennai during 1976, 1985, 2005 and 2008. Mohan et al (1999) and Suriya \& Mudgal (2012) conducted the flood hazard studies on Adyar River, utilizing either the daily rainfall data or hourly rainfall data derived from the IMD empirical reduction formula. Since radar rainfall data is available at high spatial and temporal resolution, it would be an efficient input for urban flood modelling studies.

\section{Conclusion}

Due to the technological advancement, the DWR derived rainfall data is a precious input for hydrological modelling. It was observed that the CDR's S-band DWR derived radar rainfall data was underestimating the rainfall for the study period. Consequently, the radar derived rainfall data was calibrated before using it as an input to the hydrological model. After the calibration, there was better agreement between the accumulated radar derived rainfall values and the rain gauge values.

HEC-HMS simulation results for model calibration and validation was in agreement with the observed data. The study area has a sufficient rain gauge density and the difference in the runoff volume was minimal but the variation in peak flow was significant. Therefore, the use of radar data may be elective for runoff volume estimation at the watershed with a sufficient rain gauge network, but highly desirable for peak flow and time to peak estimation, especially in urban flood modelling. IMD operates 14 Doppler weather radars across India and their products are available at adequate spatial and temporal resolutions. Hence, radar rainfall data can be a valuable input for the estimation of runoff volume, peak flow and flood-related studies.

\section{References}

Bhatnagar A K, Rajesh R P, Kalyanasundaram S, Thampi S B, Suresh R and Gupta J P 2003 Doppler radar A detecting tool and measuring instrument in meteorology. Curr. Sci. 85(3): 256-264

Bhowmik S K R, Roy S S, Srivastava K, Mukhopadhay B, Thampi S B, Reddy Y K, Singh H, Venkateswarlu S and Adhikary S 2011 Processing of Indian Doppler weather radar data for mesoscale applications. Meteorology and Atmospheric Phys. 111: 133-147 
Guhathakurta P and Rajeevan M 2008 Trends in the rainfall pattern over India. Int. J. Climatol. 28: 14531469

Habib E, Qin L, Seo D, Ciach G J and Nelson B R 2013 Independent assessment of incremental complexity in NWS multisensor precipitation estimator algorithms. J. Hydrol. Eng. 18(2): 143-155

Hammouri N and El-Naqa A 2007 Hydrological modeling of ungauged wadis in arid environments using GIS: A case study of Wadi Madoneh in Jordan. Revista Mexicana de Ciencias Geológicas 24(2): 185-196

Jeremy G 2011 Peak flow and runoff volume estimation using historical weather radar maps. Proc. AECOM Manitoba, Canada

Kathol J, Werner H and Trooien T 2003 Predicting runoff for frequency based storms using a precipitationrunoff model. Proceedings of the North-Central Intersectional Meeting of the American Society of Agricultural Engineers (ASAE) and Canadian Society of Agricultural Engineers (CSAE), Fargo North Dakota: St. Joseph, MI, ASAE Paper RRV03-0046

Kitzmiller D, Miller D, Fulton R and Ding F 2013 Radar and multisensor precipitation estimation techniques in National Weather Service hydrologic operations. J. Hydrol. Eng. 18(2): 133-142

Knapp H V, Singh J and Andrew K 2007 Hydrologic modeling of climate scenarios for two Illinois watersheds. Watershed Science Section, Illinois State Water Survey, Project Report, 2004-07

Mapiam P P, Sharma A, Chumchean S and Sriwongsitanon N 2009 Runoff estimation using radar and rain gage data. 18th World IMACS/MODSIM Congress, Cairns, Australia

Mazari N, Xie H, Zeitler J and Sharif H 2013 Validation of the NEXRAD DSP product with a dense rain gauge network. J. Hydrol. Eng. 18(2): 156-167

Mazumdar A B, Khole M and Devi S S 2009 Cyclones and depression over the North Indian Ocean during 2009. MAUSAM 61(3): 271-290

Mohan S, Raman H and Srinivasaraju K 1999 Flood Simulation in Adyar river system, in Inland water resources, India. (Eds) Durga Prasad M K and Pitchaiah P S, New Delhi: Discovery Publishing House, 330-339

Pathak C 2013 Special issue on radar rainfall data analyses and applications. J. Hydrol. Eng. 18(2): 131-132

Rashid M M, Faruque S B and Alam J B 2012 Modeling of Short Duration Rainfall Intensity Duration Frequency (SDRIDF) equation for Sylhet City in Bangladesh. ARPN. J. Sci. Technol. 2: 92-95

Roy S S, Lakshmanan V, Bhowmik S K R and Thampi S B 2010 Doppler weather radar based nowcasting of cyclone Ogni. J. Earth Syst. Sci. 119(2): 183-199

Ruiz-Villanueva V, Borga M, Zoccatelli D, Marchi L, Gaume E and Ehret U 2012 Extreme flood response to short-duration convective rainfall in South-West Germany. Hydrology and Earth Sci. Syst. 16: $1543-1559$

Sarkar S K and Kumar A 2007 Recent studies on cloud and precipitation phenomena for propagation characteristics over India. Indian J. Radio and Space Phys. 36: 502-513

Suresh R 2012 Forecasting and nowcasting convective weather phenomena over southern peninsula India Part I: Thunderstorms. Indian J. Radio and Space Phys. 41: 421-434

Suresh R 2010 Radar hydrology and rainfall mapping. Proceedings of the national seminar on Doppler Radar and Weather Surveillance (DRaWS-2010), Regional Meteorological Centre, Chennai, India

Suresh R, Ravichandran P K, Gupta J P, Thampi S B, Kalyanasundaram S and Rajesh R P 2005 On optimum rain rate estimation from a pulsed Doppler weather radar at Chennai. MAUSAM 56: 433-446

Suriya S and Mudgal B V 2012 Impact of urbanization on flooding: The Thirusoolam sub watershed - A case study. J. Hydrol. 412-413: 210-219

Teague A, Christian J and Bedient P 2013 Radar Rainfall Application in Distributed Hydrologic Modeling for Cypress Creek Watershed. Texas. J. Hydrol. Eng. 18(2): 219-227

USACE (United States Army Corps of Engineers) 2009 HEC Data Storage System Visual Utility Engine: HEC-DSSVue User's manual. Version 2.0

USACE (United States Army Corps of Engineers) 2010 Hydrologic Modeling System: HEC-HMS User manual. Version 3.5 